\title{
Financial Aspects of the EU's New Pact on Migration and Asylum: Towards Stronger EU-Funded Policy Implementation?
}

\author{
Iris Goldner Lang"
}

On 23 September 2020 - at the time of what seemed (but turned out not) to be the photo finish of the negotiations of the 2021-2027 Multiannual Financial Framework (MFF) - the European Commission proposed the New Pact on Migration and Asylum with the appended package of new legislative proposal. The aim of this article is to look at the financial implications of the Migration Pact and examine whether the ambitions of the new Pact are reflected in the 2021-2027 MFF. The text will try to respond to two questions. Firstly, it will examine whether the Migration Pact generates new costs for the EU and its Member States and whether these costs have been calculated into the MFF; and secondly, it will consider whether the creation of additional costs by the Migration Pact could interfere with its successful adoption and implementation.

* Prof. Dr. Iris Goldner Lang (igoldner@pravo.hr) is the Vice-Dean and the Head of the European Public Law Department at the Faculty of Law - University of Zagreb. She is a Jean Monnet Professor of EU Law, the Coordinator of the Jean Monnet Centre of Excellence on the "EU's Global Leadership in the Rule of Law" and the Holder of the UNESCO Chair on Free Movement of People, Migration and Inter-Cultural Dialogue.

I am grateful to Mr. Guy Stessens, Deputy Director, Council of the EU, and Mr. Jeroen Leaners MEP, as well as to other interviewees from the European Commission, the Council of the European Union and the European Parliament, who preferred to stay anonymous. The usual disclaimer applies.

This chapter is based on the author's Odysseus blog post and her paper, titled "Financial Implications of the EU's New Pact on Migration and Asylum: Will the Next Multiannual Financial Framework Cover the Costs?", published in the book on The Future of Legal Europe: Will We Trust in It?, by Springer in 2021. 


\section{Introduction}

On 23 September 2020 - at the time of what seemed (but turned out not) to be the photo finish of the negotiations of the 2021-2027 Multiannual Financial Framework (MFF) - the European Commission proposed the New Pact on Migration and Asylum (Migration Pact) with the appended package of new legislative proposal. ${ }^{1}$ The aim of this article is to look at the financial implications of the Migration Pact and examine whether the ambitions of the new Pact are reflected in the 2021-2027 MFF. The text will try to respond to two questions: Firstly, it will examine whether the Migration Pact generates new costs for the EU and its Member States and whether these costs have been calculated into the MFF and, secondly, it will consider whether the creation of additional costs by the Migration Pact could interfere with successful negotiations, adoption and implementation of the Migration Pact.

The timing of the Commission's proposal of the Migration Pact coincides with the final phase of extremely difficult negotiations on the adoption of the 2021-2027 MFF and the "Next Generation EU" recovery fund. The agreement among Member States on the new seven-year budget ended at the longest ever meeting of the European Council on 21 July 2020. According to the European Council Conclusions, EU leaders agreed that the new MFF would amount to $€ 1,074$.3 billion with an additional $€ 750$ billion for the Recovery Fund. ${ }^{2}$ Out of that amount, a total of $€ 22.7$ billion has been proposed under Heading 4 titled 'Migration and Border Management'. Out of this amount, $€ 8.7$ billion has been dedicated to Asylum and Migration Fund (AMF), ${ }^{3} € 5.5$ billion to Integrated Border Management Fund $(\mathrm{IBMF})^{4}$ and $€ 5.1$ billion to the reinforced European Border and Coast Guard Agency (EBCGA).

1 Communication from the Commission to the European Parliament, the Council, the European Economic and Social Committee and the Committee of the Regions on A New Pact On Migration And Asylum, COM(2020) 609 final, 23 September 2020. For the Migration and Asylum Package see here: $<$ https://ec.europa.eu/info/p ublications/migration-and-asylum-package_en $>$ accessed 7 November 2021.

2 Special meeting of the European Council (17, 18, 19, 20 and 21 July 2020) - Conclusions, 21 July 2020, EUCO 10/20, CO EUR 8, CONCL 4. All the amount provided in this text are in 2018 prices.

3 Proposal for a Regulation of the European Parliament and of the Council establishing the Asylum and Migration Fund, COM/2018/471 final, 12 June 2018.

4 Proposal for a Regulation of the European Parliament and of the Council establishing, as part of the Integrated Border Management Fund, the instrument for 
In addition, the external dimension of migration will be an important component of the Neighbourhood, Development and International Cooperation Instrument (NDICI), 5 whose financial envelope would amount to $€ 70.8$ billion. ${ }^{6}$ In the political agreement between the European Parliament and EU Member States on 10 November 2020, it was confirmed that the total MFF would amount to $€ 1,074.3$ billion with the additional $€ 750$ billion for the Recovery Fund. When compared to the European Council conclusions from 21 July 2020, ten programmes received top-ups. Among them are also three funds important for the financing of EU migration and asylum policies. First, the Integrated Border Management Fund (IBMF) received an additional $€ 1$ billion and will now amount to $€ 6.5$ billion. Second, the European Border and Coast Guard Agency (EBCGA) received an additional $€ 0.5$ billion and now amounts to $€ 5.6$ billion. Finally, NDICI received an additional $€ 1$ billion and is thus allocated $€ 71.8$ billion.

Due to the disagreement on the rule of law conditionality, the adoption of the 2021-2027 MFF was delayed until 17 December 2020, when the Council unanimously adopted the new Regulation. ${ }^{7}$ The new MFF came into force on 1 January 2021. As opposed to the settled future of the new MFF, the future of the Migration Pact is far less certain. It is questionable whether the legislative proposals put forward by the Commission will ever be adopted and, if so, what their final versions will look like. As will be shown later in the text, precisely the financial implications of the Migration Pact are among the reasons behind the uncertain prospects of the new Pact, as they could impact both the negotiations preceding its adoption and its successful implementation.

The chapter will be structured in four sections. This introduction will be followed by an explanation of the functioning and the current state of affairs related to the new MFF, with particular focus on the funding of activities related to migration and asylum. The third section will focus on

financial support for border management and visa, COM/2018/473 final, 12 June 2018.

5 Proposal for a Regulation of the European Parliament and of the Council establishing the Neighbourhood, Development and International Cooperation Instrument, COM/2018/460 final, 14 June 2018.

6 Beatrix Immenkamp, 'EU Legislation in Progress: 2021-2027 MFF. A new neighbourhood, development and international cooperation instrument: Proposal for a new regulation' (European Parliamentary Research Service PE 628.251, Brussels July 2021) 1-11.

7 Council Regulation (EU, Euratom) 2020/2093 of 17 December 2020 laying down the multiannual financial framework for the years 2021 to 2027, OJ L 433 I/11, 22 December 2020. 
the Migration Pact and examine the financial implications of screening, border procedures and relocations by considering whether the costs of these activities have been calculated in the new MFF and, if so, how and to what degree. The concluding section will discuss whether the costs of the novelties foreseen by the Migration Pact could interfere with its successful adoption and implementation.

\section{EU Migration and Asylum Policies in the 2021-2027 Multiannual Financial Framework}

Generally, the asylum, migration and border control budget has taken a rather small percentage of the EU budget (e.g. 1.4\% in 2016) and it has grown rather slowly over the budgetary periods. ${ }^{8}$ This is partially due to the intergovernmental nature of these policies until the Treaty of Amsterdam and partly to their sensitivity, which has prompted Member States to prefer retaining control of the resources allocated to these policy areas.

A more ambitious asylum and migration budget has been agreed only with the 2021-2027 MFF. The previous experience of insufficient funding during the 2015/16 refugee influx, which led to the reshuffling of funds and significant use of contingency margins and flexibility instruments, is one of the factors to have spurred these developments. However, three points need to be made here.

First, the emphasis of the new MFF is on the fight against irregular migration and smuggling, and border-control capacity building. Consequently, the proposal suggests a significant increase in allocations to the external dimension of migration management and asylum and a comparably smaller raise for their internal dimension. The fact that the budget for these policies is undergoing the highest increase in relative terms supports the argument that it is politically easier to negotiate a budgetary increase in this politically sensitive area than to reach an EU-wide agreement on a change of EU migration and asylum legislation, such as the one proposed by the Migration Pact.

8 For an analysis of the use of EU funds for migration, asylum and integration in the 2014-2020 budgetary period, see Darvas Zsolt and others, 'EU Funds for migration, asylum and integration policies' (Study for the European Parliament PE 603.828, Brussels April 2018) 1-52. See also Rachel Westerby, 'Follow th€ Money II: Assessing the use of EU Asylum, Migration and Integration Fund (AMIF) funding at the national level 2014-2018' (United Nations High Commissioner for Refugees and European Council on Refugees and Exiles, Brussels 2018) 1-64. 
Second, the amounts agreed for migration and asylum in the 2021-2017 MFF represent a significant increase in comparison to the 2014-2020 $€ 10$ billion budget spent on migration and asylum. However, at the same time they also amount to a $26 \%$ decrease in comparison to the $€ 31$ billion proposed by the Commission for the new budgetary period.

Finally, whereas the EU budget plays only a complementary role and is not intended to replace national expenditures in the areas of migration and asylum, the fact remains that the general EU budget - including funds for migration and asylum - remains too modest to cover the actual needs. Only a more radical reshaping of EU resources would enable the EU budget to cover the costs more substantially than it does today. Despite these difficulties associated with the MFF in general, the new EU migration and asylum budget is a step in the right direction, as it aims to respond to some of the most pressing challenges in the area of migration and asylum.

\section{Financial Implications of the Migration Pact}

The Migration Pact consists of nine instruments. ${ }^{9}$ Five of them are Commission proposals for regulations and four are soft law instruments, three of which are recommendations and one a guidance. This chapter will focus on three legislative proposals: the Proposal for a Regulation introducing screening of third-country nationals at the external borders (further in text: Screening Proposal), ${ }^{10}$ the Amended proposal for a Regulation establishing a common procedure for international protection in the Union and repealing Directive 2013/32/EU (further in text: Amended Asylum

9 For an overview of the main novelties and challenges of the Migration Pact, see Daniel Thym, 'European Realpolitik: Legislative Uncertainties and Operational Pitfalls of the "New" Pact on Migration and Asylum' (EU Migration Law Blog, 28 September 2020) <http://eumigrationlawblog.eu/european-realpolitik-legislative-u ncertainties-und-operational-pitfalls-of-the-new-pact-on-migration-and-asylum/> accessed 7 November 2021.

10 Proposal for a Regulation of the European Parliament and of the Council introducing a screening of third country nationals at the external borders and amending Regulations (EC) No 767/2008, (EU) 2017/2226, (EU) 2018/1240 and (EU) 2019/817, COM(2020) 612 final, 23 September 2020. 
Procedures Proposal $)^{11}$ and the Proposal for a Regulation on asylum and migration management (further in text: Management Proposal). ${ }^{12}$

Based on the explanatory memoranda of all the Commission's legislative proposals contained in the Migration pact, including the Screening Proposal, the Amended Asylum Procedures Proposal and the Management Proposal, all expenses resulting from the Migration Pact can be covered under the new MFF. ${ }^{13}$ Consequently, no additional financial or human resources are requested based on the wording of the legislative proposals. However, the proceeding analysis will show that it is questionable to what degree the new MFF can cover the costs of the new tasks envisaged by the Proposal for two reasons. First, the usual co-financing rate for the AMF and the BMVI is $75 \%$ of the total eligible expenditure of the activity, meaning that Member States have to cover the rest of the costs. Second, financial implications of the Migration Pact could neither be taken into consideration in the Commission's proposal of the new MFF, which was drafted much before the Migration Pact, nor were they considered in the Member States' negotiations on the 2021-2027 MFF and it remains to be seen whether the resources contained in the thematic facility - which is the flexible part of the AMF and the BMVI - will suffice to cover the Member States' needs.

This section will be divided into three sub-sections. It will, first, discuss financial implications of screening procedures, then of border procedures and, finally, of relocations. Each sub-section will first briefly outline the main elements of each of the three procedures, which is necessary in order to understand their financial implications.

\section{a) Financial Implications of Screening Procedures}

The aim of screening procedures - as regulated by the Screening Proposal - is to strengthen the control of persons entering the Schengen area and

11 Amended proposal for a Regulation of the European Parliament and of the Council establishing a common procedure for international protection in the Union and repealing Directive 2013/32/EU, COM/2020/611 final, 23 September 2020.

12 Proposal for a Regulation of the European Parliament and of the Council on asylum and migration management and amending Council Directive (EC) 2003/109 and the proposed Regulation (EU) XXX/XXX [Asylum and Migration Fund], $\operatorname{COM}(2020) 610$ final, 23 September 2020.

13 See, e.g. point 4 of the Explanatory Memorandum of the Screening Proposal and point 4 of the Explanatory Memorandum of the Management Proposal. 
refer them to the appropriate procedure. ${ }^{14}$ During the procedure, thirdcountry nationals are not allowed to enter the territory of the Member State unless it becomes apparent, during the screening, that they meet the entry conditions as required by the Schengen Borders Code. ${ }^{15}$ According to the Screening Proposal, screening applies to all third-country nationals who have crossed the external border in an unauthorised manner, to those who have applied for international protection during border checks without fulfilling entry conditions, as well as to those disembarked after a search and rescue operation. ${ }^{16}$ It is performed by national authorities, which may be assisted by the European Border and Coast Guard Agency and the European Union Agency for Asylum. ${ }^{17}$ Additionally, each Member State has to establish an independent monitoring mechanism to ensure compliance with fundamental rights. ${ }^{18}$

Point 4 of the Explanatory Memorandum of the Screening Proposal estimates that the financial resources necessary for the implementation of the Proposal are $€ 417626$ million for the period 2021-2027. It further provides that the Proposal "has implications for the EU budget" and continues that "the following elements of the screening will potentially require financial support: infrastructure for the screening: creation and use/ upgrade of the existing premises at the Border Crossing Points and reception centres; access to the relevant databases at new locations; hiring of additional staff to carry out the screening; training of border guards and other staff to carry out the screening; recruitment of medical staff; medical equipment and premises for the preliminary health checks, where appropriate; and setting up the independent monitoring mechanism of fundamental rights during the screening." However, point 4 further provides that "the expenses related to these new tasks can be covered by the resources available to the Member States under the new MFF" and that "no additional financial or human resources are requested" from the EU budget.

This opens up the question to what degree the tasks stipulated by the Screening Proposal can be covered by the new MFF. As explained previously, the costs of any new tasks envisaged by the Screening Proposal could not be included in the Commission's proposal of the new MFF, as it was drafted in 2018, much before the Screening Proposal was put forward.

14 Art 1 of the Screening Proposal.

15 Art 4 of the Screening Proposal.

16 Art 1 of the Screening Proposal.

17 Art 6(7) of the Screening Proposal.

18 Art 7(2) of the Screening Proposal. 
These costs were also not subject to negotiations on the MFF among the Member States and between the Council and the European Parliament. For this reason, any new costs resulting from the Screening Proposal could not have been calculated into the costs covered by the MFF. However, a number of tasks proposed by the Screening Proposal are actually not new, so their costs are not new. ${ }^{19}$ Identity, registration and security checks, as well as preliminary vulnerability assessments - as the mandatory elements of the screening exercise prescribed by Art. 6(6) of the Screening Proposal - are already part of Member States' obligations based on the Schengen Borders Code and the Eurodac Regulation. On the other hand, even though health checks have not been prescribed by EU migration and asylum law so far, Member States have, in practice, started conducting them in response to the COVID-19 pandemic. However, in case of the adoption of the Screening Proposal, health checks will become one of the Member States' obligations stemming from EU law and applicable also in the pandemic-free times. Nevertheless, it is questionable to what degree Member States will be able to acquire EU funding for the costs of health checks, which will encompass the recruitment of medical staff, the purchase of medical equipment and ensuring adequate premises.

Additionally, the screening procedure will result in a de-briefing form containing the information as to whether the person should be directed to the asylum, border or return procedure. This is likely to require the hiring of extra staff and their training, which will create new costs for Member States. Further, the Screening Proposal envisages the establishment of an independent monitoring mechanism. This will also create additional costs, which have not been envisaged by the MFF, as such a mechanism will require the presence of lawyers, NGOs and other staff/bodies at the external borders and their likely further engagement in the form or writing reports and recommendations. Also, Art. 6(1) of the Screening Proposal envisages that the screening takes place "at locations situated at or in proximity to the external borders". In many Member States this is likely to require the adjustment and upgrading of border infrastructure, as well as enabling access to relevant databases at the external borders. Finally, since all these activities are going to take place at the borders, without authorizing thirdcountry nationals to enter the territory of a Member State and preventing

19 For an analysis what is new and old in the Screening Proposal, see Lyra Jakulevičiene, 'Re-decoration of existing practices? Proposed screening procedures at the EU external borders' (EU Migration Law Blog, 27 October 2020) <https://eumigra tionlawblog.eu/re-decoration-of-existing-practices-proposed-screening-procedures -at-the-eu-external-borders/> accessed 7 November 2021. 
their absconding, Member States will have to create sizable facilities where third-country nationals will be accommodated during the screening and border procedures. ${ }^{20}$

Consequently, even though a number of tasks envisaged by the Screening Proposal will not be new, one can expect a considerable increase of Member States' costs related to the activities and the infrastructure needed at the external borders. It is questionable how much of these new costs will, in the end, be covered from the EU budget and how much will fall on national budgets, primarily of frontline Member States, which create the EU's external borders. Namely, the relevant EU funding instrument for the task encompassed by the Screening Proposal - as well as for other activities related to border management - is the BMVI, which is part of IBMF. ${ }^{21}$ Based on the 2018 IBMF Proposal, in the 2021-2027 budgetary period $60 \%$ of the IBMF will be allocated to the Member States' predetermined national programmes, whereas the remaining $40 \%$ of the total IBMF envelope, i.e. $€ 3207000000$, will be allocated to the thematic facility, which enables flexibility by allowing the disbursement of IBMF funds for Member States' specific actions, Union actions and emergency assistance, all based on the initiative of the Commission..$^{22}$ Consequently, $40 \%$ of IBMF is flexible, meaning that it could be used to finance the activities which have not been initially planned. However, it is difficult to predict which initially unanticipated activities will in the end be covered from the thematic facility, especially in case Member States' demands for the flexible part of the IBMF envelope exceed the available resources.

Additionally, even in cases in which the Commission decides to financially support new costs resulting from the implementation of the Screening Proposal, the contribution from the EU budget will not cover the total expenditure of the task. In most cases, the Union co-financing rate will not exceed $75 \%$ of the total expenditure of a project. ${ }^{23}$ In exceptional cases, the Union contribution can be increased to $90 \%$ for actions listed in Annex IV of the IBMF Proposal and for specific actions of high EU added

20 For the discussion on border procedurs, see sub-section 3.2.

21 See Point 3.1 of the Legislative Financial Statement Annexted to the Screening Proposal, which provides that that the budget line expenditure for the tasks encompassed by the Screening Proposal is Heading 4 of the MFF, more particularly BMVI, as part of IBMF.

22 Point 4 of the Explanatory Memorandum and Art $7(2)(b)$ and $8(1)$ of the IBMF Proposal.

23 Art 11 of the IBMF Proposal. 
value, which are defined by the Commission in its work programmes. ${ }^{24}$ Full 100\% funding may be granted for operating support and emergency assistance, whereas the Commission sets the co-financing rate and the maximum support from IBMF. ${ }^{25}$ Consequently, with the adoption of the Screening Proposal, Member States - primarily frontline ones - will face a number of financial uncertainties associated with its implementation. They will certainly have additional implementation costs and it is questionable to what degree and at which co-financing rates these costs will be covered from the EU budget.

\section{b) Financial Implications of Border Procedures}

Once the screening procedure is over, third-country nationals are channelled into asylum, border or return procedures. Border procedures are a novelty, stipulated by the Amended Asylum Procedures Directive. The aim of a border procedure is "to quickly assess at the external borders whether applications are unfounded or inadmissible and to swiftly return those with no right to stay", thus enabling Member States "to require applicants for international protection to stay at the external border or in a transit zone in order to assess the admissibility of applications ". ${ }^{26}$ Consequently, border procedures are conceptualised as a novel, pre-entry step, whereby asylum applications would be assessed without authorizing the applicants' entry into the Member State's territory and, in case of a negative decision, a return border procedure would follow immediately.

Even though border procedures do not preclude the host Member State from carrying out the procedure for determining which Member State is responsible for examining the asylum application, based on the Management Proposal, the intention behind the Amended Asylum Procedures Proposal obviously was to encourage a widespread use of border procedures in frontline Member States. Generally, national authorities are entitled to choose whether to channel the asylum applicant to a border procedure or a regular asylum procedure. ${ }^{27}$ However, it is likely that, in most cases, they will prefer to keep asylum applicants at the external borders, instead of allowing them to enter deeper into the national territory.

24 Ibid.

25 Ibid.

26 Recital 40a of the Preamble to the Amended Asylum Procedures Proposal.

27 Art 41(1) of the Amended Asylum Proposal. 
Additionally, border procedures will be compulsory in three cases: where an asylum seeker has presented false documents, where they are considered a danger to national security or public order, or in case the applicant is of a nationality (or in case of a stateless person, is a former habitual resident) of a third country with the refugee recognition rate below $20 \%$, unless the circumstances in that country have changed or the asylum seeker belongs to a category of persons for whom the low recognition rate is not representative. ${ }^{28}$

The whole procedure is intended to be highly efficient and fast. Border procedures should not exceed 12 weeks, starting from the date when the application is registered for the first time, with an additional 12-week time limit for the return procedure. ${ }^{29}$ The short time limit poses considerable risks both in terms of the protection of applicants' rights and the feasibility of the whole procedure, especially in case of high numbers of arrivals. Even though the Amended Asylum Procedures Proposal provides an elaborate framework aimed at ensuring applicants' fundamental rights and the right to an effective remedy, it is questionable whether the frontline Member States will have enough financial, operational and human resources to implement and respect these rules in practice. ${ }^{30}$

Generally, any new procedure which sets additional operational and administrative requirements on Member States inevitably generates new financial costs. First, frontline Member States will have to hire and train additional staff in order to comply with the 12-week time limit, while at the same time respecting applicants' rights. Second, the facts that border procedures will take place at the external borders and that they will preclude the applicants' entry into the Member States' territories has two implications. First, it implies that Member States will resort to detention during the 12-week period and will, consequently, have to make significant investments in setting up the adequate infrastructure for that

28 Art 40(1)(c), (f) and (i)) of the Amended Asylum Proposal. By way of exception, a Member State is not required to apply border procedures for nationals of a thirdparty country that does not cooperate sufficiently in readmission (Art 41(4)). Additionally, the application of border procedures is limited with regard to unaccompanied minors, who can be subject to border procedures only provided they come from a safe third country, are considered a threat to national security or public order or have presented false documents (Art 41(5)). Finally, border procedures do not apply to vulnerable applicants in case adequate support cannot be provided within the framework of the border procedure (Art 19(3)).

29 Art 41(11) of the Amended Asylum Procedures Proposal.

30 Art 53 of the Amended Asylum Proposal. 
purpose. ${ }^{31}$ Second, the whole border procedure will - in line with its name - take place at the external borders, thus requiring the setting up of necessary facilities where all the border activities will take place. Even though Member States do not need to set up such facilities at every border crossing point or at every section of the external borders where migrants might be apprehended or disembarked and they can choose the locations anywhere close to the external borders and transfer applicants to these locations, regardless of where the application was initially made, border facilities should be located in such a way "to avoid too many and overly time consuming transfers". ${ }^{32}$ Consequently, the implementation of border procedures will be a highly costly and demanding task, which will fall on the shoulders of frontline Member States.

Again, it is questionable whether the frontline Member States will have sufficient financial resources to be up to task. Insufficient investment in border procedures will result in poor implementation of the Migration Pact and serious violations of third-country nationals' rights. It will also trigger increased discontent of frontline Member States and mutual accusations among Member States and EU institutions. Consequently, without sufficient EU financial support, border procedures could do more harm than good.

According to the Explanatory Memorandum of the Amended Asylum Procedures Proposal, Member States will be able to make use of the AMF funds in order to support investments in the infrastructure created for the purpose of border procedures, while the European Asylum Support Office (EASO) and Frontex will be able to support Member States with staff within their respective mandates. ${ }^{33}$ However - as in the case of the financial support for screening from BMVI, which was discussed in the previous section - it remains to be seen whether the AMF will contain sufficient funds for all the Member States' needs. Again, as in the case of BMVI, potential EU financial support would come from the thematic facility, which amounts to $40 \%$ of the total financial envelope of the AMF

31 Art 41a(7) and Recitals 40f, 40h and 40i of the Preamble to the Amended Asylum Procedures Proposal. According to Recital 40f of the Preamble, detention is not compulsory, but Member States "should nevertheless be able to apply the grounds for detention during the border procedure in accordance with the provisions of the [Reception Conditions] Directive".

32 Point 4 on page 15 of the Explanatory Memorandum of the Amended Asylum Procedures Proposal.

33 Point 4 on page 12 of the Explanatory Memorandum of the Amended Asylum Procedures Proposal. 
and which enables flexibility for the actions which have not been initially planned. ${ }^{34}$ According to the Explanatory Memorandum of the Amended Asylum Procedures Proposal, it is expected that the resources contained in the AMF will be sufficient. Only time can confirm the accuracy of this presumption. In any case, the Explanatory Memorandum provides that "the Proposal does not impose any financial or administrative burden on the Union" and "has no impact on the Union budget". 35

Additionally, the Union co-financing rate from the AMF will in most cases not exceed $75 \%$ of the total expenditure of the project. ${ }^{36}$ It can, exceptionally, be increased to $90 \%$ for actions listed in Annex IV of the AMF Proposal and for specific actions of high Union value. ${ }^{37}$ Full 100\% funding could be granted for operational support and for emergency assistance. ${ }^{38}$ The co-financing rate for Union support to border procedures will depend on the Commission's decision, so it cannot be predicted at this stage.

\section{c) Financial Incentives for Solidarity: EU Budgetary Plans for Relocations}

Over the past decade, solidarity has been one of the most burning and controversial issues of EU migration and asylum policies. In this context, relocations were one of the main stumbling blocks in finding a solution that would be acceptable to all Member States and EU institutions. The Management Proposal aims to find a compromise among opposed national interests by enabling Member States to choose (to a certain degree) among different solidarity tools offered by the Management Proposal when providing help to the most pressured Member States. The Proposal introduces a 'solidarity pool' - a set of solidarity contributions benefiting a Member State under migratory pressures or subject to disembarkations following search and rescue operations. ${ }^{39}$ Solidarity contributions consist of relocations of asylum seekers who are not subject to border procedures, relocations of asylees, 'return sponsorships' of illegally staying third-coun-

34 According to Art 8 of the AMF, out of $€ 10415000000$ of the total financial envelope, $€ 6249000000$ will be allocated to the programmes implemented under shared management and $€ 4166000000$ to the thematic facility.

35 Point 4 on page 12 of the Explanatory Memorandum of the Amended Asylum Procedures Proposal.

36 Art 12 of the AMF Proposal.

37 Ibid.

38 Ibid.

39 Art 45(1) of the Management Proposal. 
try nationals and capacity-building and operational support measures in the Member State under migratory pressure. ${ }^{40}$ The share of solidarity contributions by each Member State will be calculated based on the size of the population (50\% weighing) and the total GDP (50\% weighing). ${ }^{41}$ Even though Member States are free to choose solidarity contributions, the Management Proposal provides a correction mechanism in order to prevent a situation where they would mainly or only choose capacity-building and operational support, thus completely avoiding relocations and return sponsorship. ${ }^{42}$

This chapter will not go into the analysis (and critique) of the issue whether solidarity arrangements set by the Management Proposal respond to the actual needs of the most affected, frontline Member States. ${ }^{43}$ The aim of the following paragraphs is to examine whether relocations - as the most contentious solidarity tool - will be covered from the EU budget and, if so, whether the amounts allocated for relocations will be a sufficient incentive to encourage Member States to choose relocations from the 'solidarity pool' set by the Management Proposal.

The Management Proposal foresees that transfer costs for relocations will be paid from the thematic facility of the AMF, mainly through direct management or, depending on the situation, through shared management, by topping up national programmes. ${ }^{44}$ The AMF foresees relocations as one of the possible uses of the AMF thematic facility. However, it does not envisage a special financial envelope which would be allocated exclusively for relocations. ${ }^{45}$ For this reason, the Management Proposal has an additional role of amending the future AMF Regulation. This is visible both from its title and from Art. 72, which stipulates that Member States will re-

40 Ibid.

41 Art 54 of the Management Proposal.

42 Art 48(2) and 53(2) of the Management Proposal.

43 On the analysis of solidarity in the Migration Pact, see Francesco Maiani, 'A "Fresh Start" or One More Clunker? Dublin and Solidarity in the New Pact' (EU Migration Law Blog, 20 October 2020) <http://eumigrationlawblog.eu/a-fresh -start-or-one-more-clunker-dublin-and-solidarity-in-the-new-pact/> accessed 7 November 2021. For the discussion of solidarity in the context of the refugee crisis, see Iris Goldner Lang, 'The EU Financial and Migration Crises: Two Crises - Many Facets of Solidarity' in Andrea Biondi, Egle Dagilytė and Esin Küçük (eds), Solidarity in EU Law: Legal Principle in the Making (Edward Elgar Publishing 2018) 133-160.

44 Point 1.6. of the Legislative Financial Statement Annexed to the Management Proposal.

45 Point 2.2. of the Legislative Financial Statement Annexed to the AMF Proposal. 
ceive a $€ 10000$ contribution for each relocation of asylum seekers, asylees and illegally staying third-country nationals subject to return sponsorship, whereas the contribution is increased to $€ 12000$ for unaccompanied minors. ${ }^{46}$ The same allocations apply in case of resettlements. ${ }^{47}$ This approach, whereby a legal act is amended by adopting a completely different act, might not be the conventional way to make legislative changes. However, it is understandable considering the fact that the European Commission did not want to make changes to its AMF Proposal at the last moment before the trialogues, as this would probably prolong the procedure and delay its adoption.

Point 4 of the Explanatory Memorandum of the Management Proposal specifies that the total financial resources needed for the implementation of the Management Proposal for the period from 2021 until 2027 will amount to $€ 1113500$ million, which should cover the costs of all relocations. ${ }^{48}$ This is a significant amount, but in case more asylum seekers would need to be relocated and transferred, the Management Proposal suggests that additional resources should be requested. ${ }^{49}$ The lump sums of $€ 10000$ and $€ 12000$ are also considerable, but it is questionable whether they will create a sufficient incentive for Member States to opt for more relocations.

The experience from the two Relocation Decisions from 2015 is not promising. These Decisions were adopted in the midst of the 2015/2016 refugee influx. ${ }^{50}$ Both decisions stipulated that the Member State of relocation would receive a lump sum of $€ 6000$ for each relocation. ${ }^{51}$ The adoption of the Relocation Decisions was openly opposed by Slovakia, Romania, Hungary and the Czech Republic, which voted against the second Relocation Decisions during the qualified majority voting in the Council of Ministers. Slovakia and Hungary started annulment actions against the second Relocation Decision before the Court of Justice, calling into question

46 Art 72(2) of the Management Proposal.

47 Art 72(1) of the Management Proposal.

48 Point 4 of the Explanatory Memorandum of the Management Proposal.

49 Ibid.

50 Council Decision (EU) 2015/1523 of 14 September 2015 establishing provisional measures in the area of international protection for the benefit of Italy and of Greece, OJ L 239, 15 September 2015; Council Decision (EU) 2015/1601 of 22 September 2015 establishing provisional measures in the area of international protection for the benefit of Italy and Greece, OJ L 248, 24 September 2015.

51 Art 10 of both Relocation Decisions. 
its legality, but the Court dismissed their actions. ${ }^{52}$ Most importantly, after the expiry of the two-year implementation period of the two Relocation Decisions, the results were disappointing. Out of 98256 relocations, only 34705 third-country nationals (21 999 from Greece and 12706 from Italy) were relocated. Obviously, neither the financial incentive, nor the fact that non-compliance with the prescribed relocation quotas would amount to the violation of their obligations under EU law motivated certain Member States to relocate. ${ }^{53}$ The lump sums offered by the Management Proposals are more generous than the ones prescribed by the Relocation Decisions, but it is questionable whether this will make a change.

\section{Concluding Remarks: The Impact of Financial Costs on the Implementation of the Migration Pact}

The implementation of the Migration Pact - in particular screening, border procedures and relocations - will generate considerable financial costs due to new procedures and administrative and operational requirements they impose on Member States. The implementation of the Pact will demand new infrastructure, equipment, operational activities, including transfers of third-country nationals, recruitment and training of new staff, access to databases and setting up of a new independent monitoring mechanism. New tasks will mostly fall on the shoulders of frontline Member States and those states where most relocations will take place. The Management Proposal foresees considerable funding for relocations, by proposing an amendment to the new AMF, which would enable financial support to the Member States of relocation, covered from the AMF thematic facility. However, all the three legislative proposals discussed above - the Management Proposal, the Screening Proposal and the Amended Asylum Procedures Proposal - envisage that the AMF and the IBMF financial envelopes will contain sufficient funding to cover the costs incurred by the implementation of the new instruments. Whereas this might be true for relocations, it is difficult to predict whether it is accurate for border

52 ECJ, Joined Cases C-643/15 and C-647/15, Slovak Republic and Hungary $v$ Council of the European Union, ECLI:EU:C:2017:631.

53 In the end, the Commission started infringement proceedings against Poland, Hungary and the Czech Republic and the Court decided that they failed to fulfil their obligations under EU law (ECJ, Joined Cases C-715/17, C-718/17 and C-719/17, Commission v Poland, Hungary and the Czech Republic, ECLI:EU:C:2020:257). 
and screening procedures and how much of the costs will in the end be covered by national budgets, due to the limitations of the AMF and the IBMF thematic facilities, both in terms of their size and the Union co-financing rates.

One can expect that the statements about sufficient funding will not convince frontline Member States. Consequently, they will surely insist on laying down the specifics of the screening, border and return procedures that will define who does what and who pays for every single step of the procedures. The financial component of the Migration Pact will surely play a major role in the future negotiations.

Additionally, the complexity and deficiency of the rules proposed by the Migration Pact create an additional risk in terms of the link between the financial impact of the Pact and its successful implementation. The rules set by the Migration Pact, as they currently stand, will make it difficult to properly implement the new procedures and make them work in practice. High financial costs will make their implementation even more challenging, as screening, border procedures, relocations and returns can be properly implemented only provided Member States are sufficiently equipped, capacitated and trained. If this is not the case, new procedures might create the opposite effect from the desired one, as certain Member States might end up with more delays and violations of EU law, including asylum seekers' rights, than they used to have. It is questionable how the Commission will react to such violations and whether it is going to try to compensate for the deficiencies of the procedures by being reluctant to start infringement proceedings against the mostly affected, frontline Member States, in case they are not able to perform. For all these reasons, it is questionable whether the money that will be invested in the implementation of the Migration Pact will be proportionate to the outcomes of the new procedures, in case they do not satisfy the expectations, in terms of their efficiency, speed and protection of fundamental rights. 
